\title{
48-Week Outcome after Cessation of Nucleos(t)ide Analogue Treatment in Chronic Hepatitis B Patient and the Associated Factors with Relapse
}

\author{
Wen-xiong Xu $\mathbb{D}^{1,2}$ Qian Zhang $\mathbb{D}^{1,3}$ Xiang Zhu $\mathbb{D}^{1,},{ }^{1,2}$ Chao-shuang Lin $(\mathbb{D}),{ }^{1,2}$ \\ You-ming Chen $\mathbb{D}^{1},{ }^{1,2}$ Hong Deng $\mathbb{D}^{1},{ }^{1,2}$ Yong-yu Mei $\mathbb{D}^{1,2}$ Zhi-xin Zhao $\mathbb{D}^{1,1,2}$ \\ Dong-ying Xie $\mathbb{D},{ }^{1,2}$ Zhi-liang Gao $\mathbb{D},,^{1,2}$ Chan Xie $\mathbb{D},,^{1,2}$ and Liang Peng $\mathbb{D}{ }^{1,2}$ \\ ${ }^{1}$ Department of Infectious Diseases, Third Affiliated Hospital of Sun Yat-sen University, Guangzhou, Guangdong 510630, China \\ ${ }^{2}$ Guangdong Key Laboratory of Liver Disease Research, Third Affiliated Hospital of Sun Yat-sen University, Guangzhou, \\ Guangdong 510630, China \\ ${ }^{3}$ Department of Infectious Diseases, Union Hospital, Tongji Medical College, Huazhong University of Science and Technology, \\ Wuhan, Hubei 430022, China
}

Correspondence should be addressed to Chan Xie; happyxiechan@hotmail.com and Liang Peng; pliang@mail.sysu.edu.cn

Wen-xiong $\mathrm{Xu}$ and Qian Zhang contributed equally to this work.

Received 5 November 2017; Revised 26 February 2018; Accepted 19 March 2018; Published 10 May 2018

Academic Editor: Kevork M. Peltekian

Copyright (c) 2018 Wen-xiong Xu et al. This is an open access article distributed under the Creative Commons Attribution License, which permits unrestricted use, distribution, and reproduction in any medium, provided the original work is properly cited.

\begin{abstract}
Background and Aims. We aimed to ascertain the feasibility and safety of NA cessation, the status of patients after cessation, and the predictive factors for relapse and subsequent retreatment. Methods. A total of 92 patients were enrolled in this prospective study. Patients were monitored every month for the first 3 months after cessation and every 3 months thereafter. Results. Sixty-two patients finished 48 weeks of follow-up. None died or developed liver failure, cirrhosis, or HCC. The 62 patients could be divided into 4 categories according to the 48-week clinical development of relapse. Virologic relapses occurred in 39 (62.9\%) patients, with $72.7 \%$ occurring in the first 24 weeks in origin $\mathrm{HBeAg}$ positive patients and $82.4 \%$ in the first 12 weeks in origin $\mathrm{HBeAg}$ negative patients. Age $(\mathrm{OR}=1.06,95 \% \mathrm{CI}=1.02-1.10 ; p=0.003)$, the HBsAg level $(\mathrm{OR}=2.21,95 \% \mathrm{CI}=1.47-3.32 ; p<0.001)$, and positive origin HBeAg status $(\mathrm{OR}=0.32,95 \% \mathrm{CI}=0.14-0.74 ; p=0.008)$ were predictive factors to virologic relapse. HBV DNA level $(\mathrm{OR}=$ $1.34,95 \% \mathrm{CI}=1.13-1.58 ; p<0.001)$ was predictive factor to retreatment. Conclusions. NA cessation is safe under supervision. Age, HBsAg level, and origin HBeAg status can be predictive factors for virologic relapse. The study was submitted to ClinicalTrials.gov Protocol Registration and Results System with the assigned NCT ID NCT02883647.
\end{abstract}

\section{Introduction}

Chronic hepatitis B virus (HBV) infection is a major health problem, as approximately 240 million people are infected worldwide [1]. Nucleos(t)ide analogues (NA) have been developed to control HBV [2], and they can strongly inhibit reverse transcriptase to suppress the HBV DNA levels but cannot erase covalently closed circular DNA (cccDNA), as it integrates into the genome in the nuclei of the host hepatocytes [3]. Therefore, most patients require long-term
NA therapy, even though HBV DNA levels are suppressed to undetectable levels in a short amount of time.

Long-term NA therapy can control chronic hepatitis B, but several problems remain. The first is the economical burden, especially in developing countries where health care and life insurance are poor. The second are poor adherence and retention in care of the patients, resulting from this high cost. The third is the side effect of the drugs, including renal and bone toxicity. The fourth are viral mutant and drug resistance which are further hindrances to drug efficacy. 
Finite NA therapy has the advantages of solving the above problems. How to make finite NA therapy is what physicians and patients concern.

Guidelines of prevention and treatment of chronic hepatitis B (CHB) from China [4], Asian Pacific Association for the Study of the Liver (APASL) [5], European Association for the Study of the Liver (EASL) [6], American Association for the Study of Liver Diseases (AASLD) [7], and World Health Organization (WHO) [8] all make suggestions on NA cessation, including parameters like NA treatment duration and consolidation treatment duration. Although physicians follow these suggestions, recent studies still indicate high virologic relapse rates ranging from $40 \%$ to $95 \%$ in the first year after NA cessation [9-12]. Some authors in these studies presented predictive factors for relapse, such as age, consolidation treatment duration, NA treatment duration, and baseline HBV DNA level. But some authors had the opposite opinion. There are, as yet, difficulties of how to stop NA therapy without relapse. Otherwise, NA cessation without supervision may result in an unpredictable worsening of disease and the possible development of cirrhosis, fulminant hepatitis, or acute-on-chronic liver failure (ACLF). Safety of NA therapy cessation and NA retreatment efficacy after relapse are very important issues that should be found out. In this study, we aimed to determine the feasibility and safety of NA cessation, the therapeutic effect of retreatment in relapsed patients, the features of patients after cessation, and the predictive factors for relapse and retreatment.

\section{Materials and Methods}

2.1. Study Population. This prospective study recruited 92 Chinese HAN outpatients with chronic hepatitis B in Third Affiliated Hospital of Sun Yat-sen University from December 2013 to January 2017. All patients were treated with nucleos(t)ide analogues, such as entecavir (ETV), telbivudine (LDT), lamivudine (LAM), adefovir dipivoxil (ADV), or a combination of LAM and ADV. Informed consent from the patients was obtained.

\subsection{Inclusion and Exclusion Criteria}

Inclusion Criteria. They include the following: (1) CHB patients (hepatitis B surface antigen [HBsAg] and HBV DNA positive for at least 6 months [5]) receiving NA therapy; (2) age from 18 to 65 years; (3) patients who had been treated with NA for at least 2 years with undetectable HBV DNA levels on at least 3 separate occasions, 6 months apart, before the cessation of treatment (otherwise, hepatitis B e antigen ( $\mathrm{HBeAg})$ seroconversion was required and maintained for at least one year in origin HBeAg positive patients); (4) HBV DNA level that were "not detected" or "<20 IU/mL," as determined by Roche COBAS detection before cessation.

Exclusion Criteria. They include the following: (1) patients with liver cirrhosis, hepatocellular carcinoma (HCC), or other malignancies; (2) patients with other factors causing liver disease; (3) pregnant or lactating women; (4) patients with concomitant HIV infection or congenital immune deficiency diseases; (5) patients with diabetes or autoimmune diseases; (6) patients with important organ dysfunctions or serious complications (e.g., infection, ascites, hepatic encephalopathy, hepatorenal syndrome, or gastrointestinal bleeding).

2.3. Follow-Up Evaluation. All patients were monitored every month for the first 3 months after cessation and every 3 months thereafter. Symptoms (e.g., fatigue, poor appetite, and jaundice), occurrence of liver cirrhosis or HCC, and mortality were all recorded for the study. Blood cells (white blood cells, red blood cells, hemoglobin, and platelets), biochemical parameters (serum aspartate transaminase [AST], alanine transaminase [ALT], total bilirubin, blood urea nitrogen [BUN], and creatinine), virologic parameters (quantitative HBsAg, HBeAg, HBeAb, and HBV DNA), T lymphocytes (CD4 positive $\mathrm{T}$ lymphocytes $\left[\mathrm{CD} 4^{+} \mathrm{T}\right]$, CD8 positive $\mathrm{T}$ lymphocytes $\left[\mathrm{CD}^{+} \mathrm{T}\right]$, Type 1 helper $\mathrm{T}$ lymphocytes [Th1], and Type 2 helper T lymphocytes [Th2]), and ultrasound results were assessed at every visit.

Routine automated techniques were used for all biochemical tests at our clinical laboratories. Serum HBsAg levels were measured using Roche Elecsys HBsAg II quant assay (range 0.05-52000 IU/mL, Roche Diagnostics, Mannheim, Germany). Serum $\mathrm{HBeAg}$ and $\mathrm{HBeAb}$ were assayed using the EIA kit (Abbott Diagnostics, North Chicago, IL). Serum HBV DNA levels were measured with real-time PCR using the COBAS AmpliPrep/COBAS TaqMan HBV Test, version 2.0 (detection limit: $20 \mathrm{IU} / \mathrm{mL}$, Roche Molecular Systems, Inc., Branchburg, NJ, USA). T lymphocytes were measured using flow cytometry analysis with a BD Accuri C6 flow cytometer according to the manufacturer's instructions.

2.4. Definition and Management of Relapse. According to guideline of prevention and treatment of chronic hepatitis $B$ from APASL [5], virologic relapse was defined as HBV DNA $>2000 \mathrm{IU} / \mathrm{mL}$, while clinical relapse was defined as $\mathrm{HBV}$ DNA > $2000 \mathrm{IU} / \mathrm{mL}$ and ALT $>2$ times upper limit of normal (ULN).

Patients Management. (1) Patients with nonrelapse would go on for the next visit. (2) Patients with virologic relapse would go on for the next visit if ALT $\leq 2$ times ULN. (3) Patients with clinical relapse would go on for the next visit if they have no symptoms and ALT $\leq 5$ times ULN. (4) Patients with clinical relapse would be retreated with NA if they have symptoms and ALT $\leq 5$ times ULN. (5) Patients with clinical relapse would be retreated with NA if ALT > 5 times ULN. Patients were monitored every month for the first 3 months after retreatment with NA and every 3 months thereafter.

2.5. Ethical Approval. Ethical approval was provided by the Ethics Committee of Medical Clinical Trials, the Third Affiliated Hospital of Sun Yat-sen University (March 20, 2015).

2.6. Statistical Analysis. Continuous data were indicated with mean \pm SD while categorical data were reported as number 
and percentage (\%). Spearman correlation coefficient was used to investigate the correlation among $\mathrm{HBsAg}, \mathrm{HBV}$ DNA, and T lymphocytes. Nonparametric tests including Mann-Whitney $U$ test and Wilcoxon signed-rank test were used to compare means between groups for data normality was not assumed.

The outcome variables included the occurrences of virologic relapse or retreatment at baseline (month 0 ) and 1, 2, 3, 6, and 12 months after cessation. Associations between independent variables and outcome variables were analyzed using univariate/multivariate generalized estimating equation (GEE) and binary logistic regression models. An independent working correlation matrix was adopted for the repeated measure data. ROC analysis was further used to assess the diagnostic effectiveness of independent variables which were found associated with outcome. The statistical significance level for all the tests was set at a $p$ value < 0.05 . Statistical analyses were performed using IBM SPSS Version 20 (SPSS Statistics V20, IBM Corporation, Somers, New York).

\section{Results}

3.1. Baseline Characteristics. A total of 92 patients treated with NA were recruited in this study. Nine of the patients were lost to follow-up, and 62 finished the 48 weeks of followup. Thirty-nine of the 62 patients were origin $\mathrm{HBeAg}$ positive before NA treatment; they gained HBeAg seroconversion before NA cessation. Twenty-three patients were origin $\mathrm{HBeAg}$ negative before NA treatment. Nineteen patients were treated with ETV for $4.55 \pm 1.93$ years before cessation, 23 patients were treated with LDT for $3.35 \pm 1.34$ years, 5 patients were treated with LAM for $5.02 \pm 2.46$ years, 7 patients were treated with $\mathrm{ADV}$ for $7.51 \pm 2.65$ years, and 8 patients were treated with combination of LAM and ADV for $4.94 \pm 2.95$ years. The flow of patient recruiting and clinical development was indicated in Figure 1. The baseline characteristics of the 62 patients were shown in Table 1.

3.2. Safety of NA Cessation. In the course of the 48 weeks of follow-up, none of the 62 patients died or developed liver failure, cirrhosis, or hepatocellular carcinoma. Twenty-one (33.9\%) patients were retreated with NA (origin NA or ETV or TDF) and regained normal ALT and undetectable HBV DNA within 24 weeks.

3.3. Four Categories in Follow-Up. According to the development of patient's levels of HBV DNA and ALT across time (from 0 to 48 weeks) and features of relapse in the follow-up, the 62 patients could be divided into 4 categories (Figures 1 and 2): Category A, consisting of 23 patients in the nonrelapse group, for whom ALT remained normal and HBV DNA levels were not higher than $2000 \mathrm{IU} / \mathrm{mL}$ during the followup; Category B, consisting of 4 patients in the virologic relapse group, for whom ALT levels were not higher than 2 ULN and HBV DNA remained above $2000 \mathrm{IU} / \mathrm{mL}$ during the followup; Category C, consisting of 14 patients in the virologic relapse group, for whom HBV DNA levels decreased into no higher than $2000 \mathrm{IU} / \mathrm{mL}$ automatically without antiviral treatment during the follow-up, changing patient status to nonrelapse; Category D, consisting of 21 patients with high ALT levels and HBV DNA levels which were sufficiently elevated during the follow-up to necessitate retreatment with $\mathrm{NA}$, in order to avoid fulminant hepatitis or cirrhosis.

3.4. Cumulative Relapse and Retreatment Rates. For all 62 patients who finished 48-week follow-up, the 48-week cumulative virologic relapse, clinical relapse, and retreatment rate were $62.9 \%, 38.7 \%$, and $33.9 \%$, respectively. For the 39 origin HBeAg positive patients, the 48 -week cumulative virologic relapse, clinical relapse, and retreatment rate were $56.4 \%$, $35.9 \%$, and $30.8 \%$, respectively. Sixteen of $22(72.7 \%)$ virologic relapses and 11 of $14(78.6 \%)$ clinical relapses occurred in the first 24 weeks in origin $\mathrm{HBeAg}$ positive patients. For the 23 origin $\mathrm{HBeAg}$ negative patients, the 48 -week cumulative virologic relapse, clinical relapse, and retreatment rate were $73.9 \%, 43.5 \%$, and $39.1 \%$, respectively. Fourteen of 17 (82.4\%) virologic relapses and 6 of $10(60 \%)$ clinical relapses occurred in the first 12 weeks in origin $\mathrm{HBeAg}$ negative patients. The results were shown in Figure 3.

3.5. $C D 4^{+} T, C D 8^{+} T$, Th1, and Th2. To further investigate the association among HBsAg, HBV DNA, and flow cytometry results, correlation analyses were used. A negative correlation was found between HBsAg and $\mathrm{CD}^{+} \mathrm{T}(r=-0.37, p<$ 0.001 ), a positive correlation was found between HBsAg and $\mathrm{CD}^{+} \mathrm{T}(r=0.37, p<0.001)$, and no correlations at all were found between HBsAg and Th1 $(p=0.832)$ or Th2 $(p=0.887)$. A negative correlation was found between $\mathrm{HBV}$ DNA and $\mathrm{CD}^{+} \mathrm{T}(r=-0.44, p<0.001)$, and no correlations at all were found between HBV DNA and $\mathrm{CD}^{+} \mathrm{T}(p=0.114)$ or Th1 $(p=0.243)$ or Th2 $(p=0.703)$. The changes in these ratios over the course of follow-up in both nonrelapse and virologic relapse patients were shown in Figure 4. No statistical significance was found between any of the groups (all $p>0.05$ ).

3.6. Predictive Factors for Virologic Relapse and Retreatment. Univariate and multivariate logistic regression under GEE models were used to investigate the possibly predictive factor for virologic relapse or retreatment. Independent variables which were not significant in univariate results would still be modeled in multivariate model as adjustment of covariates. Only the variables which reached significance in both univariate and multivariate models would be recognized as possibly predictive factor to virologic relapse or retreatment.

As shown in Table 2, age and the level of HBsAg were significant risk factors. As age and the level of $\mathrm{HBsAg}$ are increasing, the more likely patients would occur with virologic relapse. The estimated ORs (odds ratio) of age and the level of HBsAg were 1.06 (95\% CI $=1.02-1.10 ; p=0.003$ ) and 2.21 (95\% CI $=1.47-3.32 ; p<0.001)$, respectively. On the contrary, positive status of origin HBeAg before NA treatment was a protective factor. The estimated OR was 0.32 (95\% CI $=0.14-0.74 ; p=0.008)$ which means lower risk to occur with virologic relapse. 


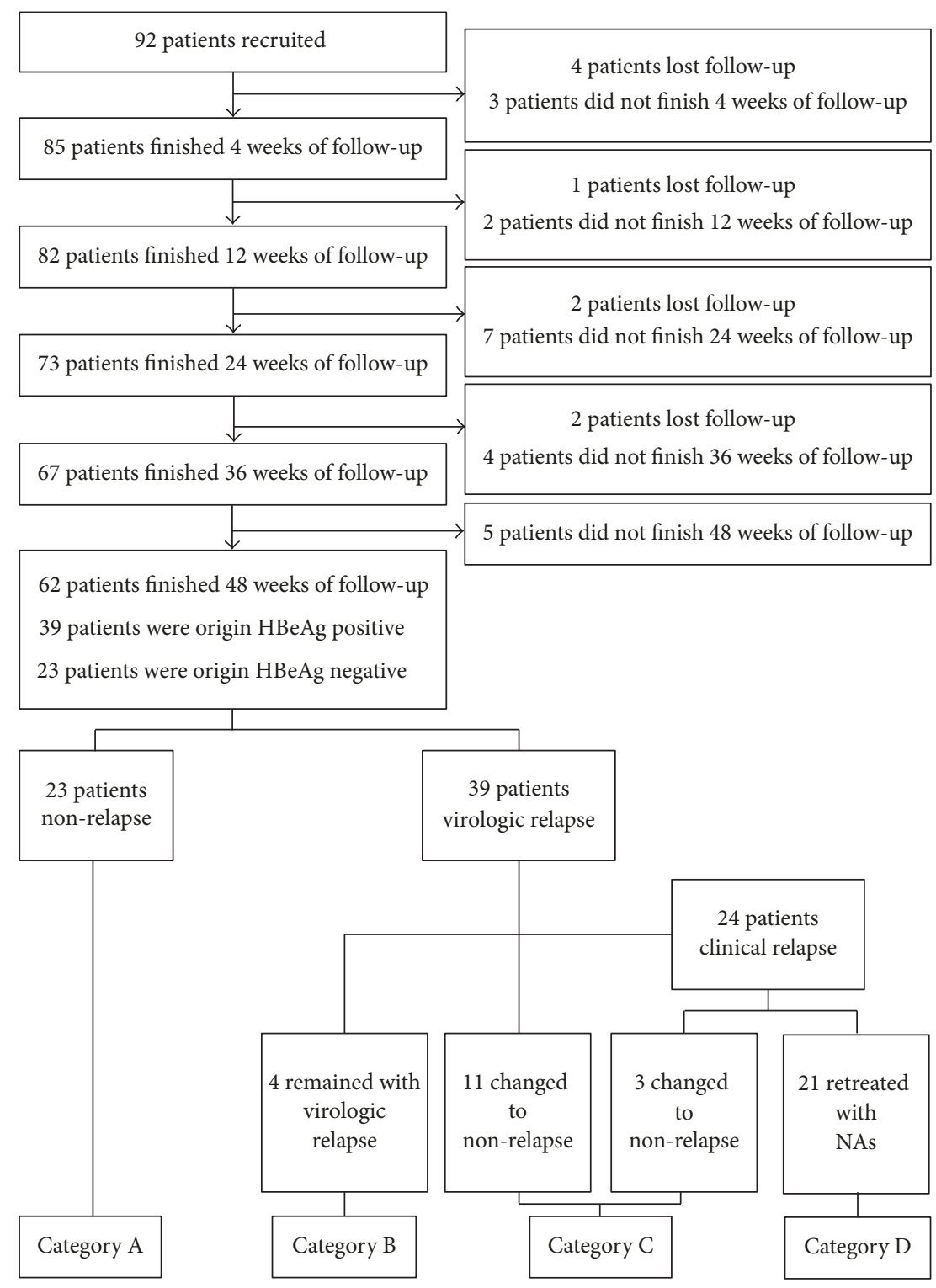

FIGURE 1: Flow chart of patient recruitment and clinical development.

TABLE 1: Baseline characteristics of 62 patients before NA treatment cessation.

\begin{tabular}{|c|c|c|c|}
\hline & $\begin{array}{l}\text { origin } \mathrm{HBeAg} \text { positive } \\
(n=39)\end{array}$ & $\begin{array}{l}\text { origin } \mathrm{HBeAg} \text { negative } \\
(n=23)\end{array}$ & $\begin{array}{c}\text { All } \\
(n=62)\end{array}$ \\
\hline Age, year & $33.18 \pm 8.33$ & $44.39 \pm 8.99$ & $37.34 \pm 10.11$ \\
\hline Gender, male (\%) & $26(66.7)$ & $19(82.6)$ & $45(72.6)$ \\
\hline $\mathrm{BMI}, \mathrm{kg} / \mathrm{cm}^{2}$ & $21.31 \pm 2.91$ & $23.01 \pm 3.12$ & $21.95 \pm 3.08$ \\
\hline $\begin{array}{l}\text { NA treatment, ratio of ETV : LDT:LAM : ADV : LAM } \\
+\mathrm{ADV}^{*}\end{array}$ & $10: 17: 3: 5: 4$ & $9: 6: 2: 2: 4$ & $19: 23: 5: 7: 8$ \\
\hline Duration of NA treatment, year & $4.64 \pm 2.63$ & $4.33 \pm 1.74$ & $4.52 \pm 2.33$ \\
\hline Duration of negative HBV DNA maintenance, year & $3.83 \pm 2.15$ & $3.68 \pm 1.31$ & $3.78 \pm 1.87$ \\
\hline Duration of $\mathrm{HBeAg}$ seroconversion maintenance, year & $3.19 \pm 2.47$ & - & - \\
\hline EOT HBsAg, $\log 10(\mathrm{IU} / \mathrm{mL})^{\#}$ & $2.65 \pm 1.22$ & $2.36 \pm 1.38$ & $2.54 \pm 1.28$ \\
\hline
\end{tabular}

${ }^{*} \mathrm{NA}$ : nucleos(t)ide analogues; ETV: entecavir; LDT: telbivudine; LAM: lamivudine; ADV: adefovir dipivoxil; ${ }^{\#}$ EOT: end of treatment. 

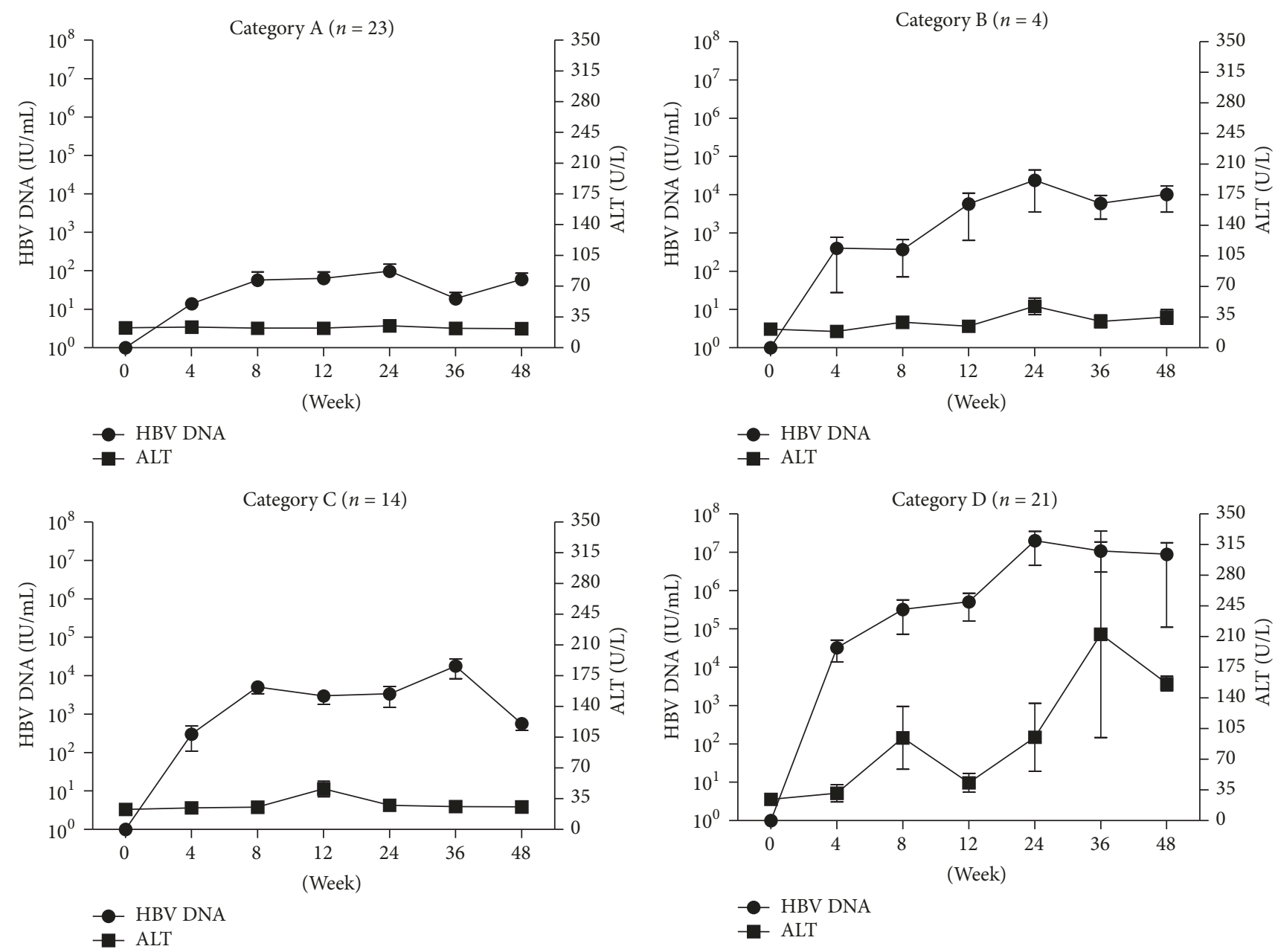

FIgURE 2: Change of levels of ALT and HBV DNA in four categories from 0 to 48 weeks.

TABLE 2: Independent variables associated with virologic relapse in GEE models.

\begin{tabular}{|c|c|c|c|c|}
\hline \multirow{2}{*}{ Parameters } & \multicolumn{2}{|c|}{ Univariate } & \multicolumn{2}{|c|}{ Multivariate } \\
\hline & OR $(95 \% \mathrm{CI})$ & $p$ & OR $(95 \% \mathrm{CI})$ & $p$ \\
\hline \multicolumn{5}{|l|}{ Sex } \\
\hline Male & Ref & - & Ref & - \\
\hline Female & $1.12(0.51-2.49)$ & 0.774 & $1.14(0.59-2.19)$ & 0.704 \\
\hline Age, year & $1.05(1.01-1.08)$ & 0.009 & $1.06(1.02-1.10)$ & 0.003 \\
\hline BMI, $\mathrm{kg} / \mathrm{m}^{2}$ & $0.97(0.87-1.09)$ & 0.617 & $0.85(0.75-0.95)$ & 0.006 \\
\hline Duration of NA treatment, year & $0.89(0.74-1.08)$ & 0.255 & $1.40(1.14-1.73)$ & 0.001 \\
\hline Duration of negative HBV DNA maintenance, year & $0.81(0.65-1.01)$ & 0.066 & $0.52(0.33-0.83)$ & 0.005 \\
\hline HBsAg, $\log 10(\mathrm{IU} / \mathrm{mL})$ & $1.79(1.32-2.45)$ & $<0.001$ & $2.21(1.47-3.32)$ & $<0.001$ \\
\hline \multicolumn{5}{|l|}{ Origin $\mathrm{HBeAg}$} \\
\hline Negative & Ref & - & Ref & - \\
\hline Positive & $0.38(0.19-0.79)$ & 0.010 & $0.32(0.14-0.74)$ & 0.008 \\
\hline
\end{tabular}

The results of retreatment were indicated in Table 3. The level HBV DNA was found to be the only variable which was significant in both univariate and multivariate models. The estimated OR of HBV DNA was $1.34(95 \% \mathrm{CI}=1.13-1.58$; $p<$ 0.001 ) which means every unit increased would increase 1.34 times of odds of needing retreatment.
ROC analysis was further used to investigate the diagnostic effectiveness of these associated factors. As indicated in Figure 5, the results of age to virologic relapse (Figure 5(a)), the level of HBsAg to virologic relapse (Figure 5(b)), and the level of HBsAg to clinical relapse (Figure 5(c)) all showed significant diagnostic effectiveness (all $p<0.05$ ). The optimal 

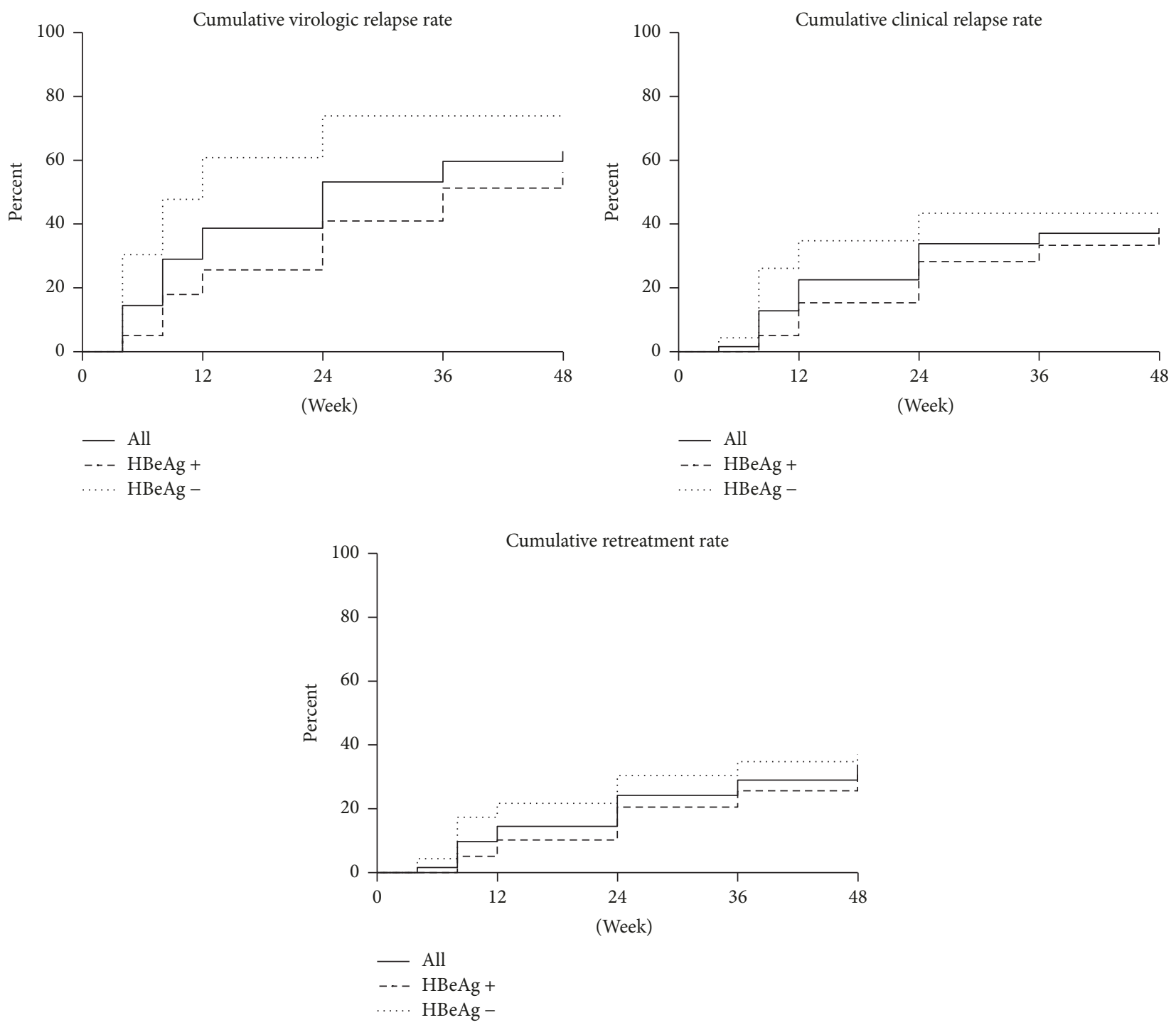

FIGURE 3: Forty-eight-week cumulative rates of virologic relapse, clinical relapse, and retreatment.

TABLE 3: Independent variables associated with retreatment in GEE models.

\begin{tabular}{|c|c|c|c|c|}
\hline \multirow{2}{*}{ Parameters } & \multicolumn{2}{|c|}{ Univariate } & \multicolumn{2}{|c|}{ Multivariate } \\
\hline & OR $(95 \% \mathrm{CI})$ & $p$ & OR $(95 \% \mathrm{CI})$ & $p$ \\
\hline \multicolumn{5}{|l|}{ Sex } \\
\hline Male & Ref & - & Ref & - \\
\hline Female & $1.75(0.42-7.35)$ & 0.445 & $2.17(0.45-10.43)$ & 0.332 \\
\hline Age, year & $1.06(0.98-1.14)$ & 0.177 & $1.04(0.92-1.18)$ & 0.490 \\
\hline BMI, $\mathrm{kg} / \mathrm{m}^{2}$ & $1.00(0.80-1.26)$ & 0.975 & $1.02(0.78-1.34)$ & 0.878 \\
\hline Duration of NA treatment, year & $1.25(0.81-1.95)$ & 0.314 & $1.08(0.53-2.20)$ & 0.830 \\
\hline Duration of negative HBV DNA maintenance, year & $1.45(0.90-2.33)$ & 0.130 & $1.11(0.42-2.91)$ & 0.830 \\
\hline HBV DNA, $\log 10(\mathrm{IU} / \mathrm{mL})$ & $1.28(1.08-1.50)$ & 0.003 & $1.34(1.13-1.58)$ & $<0.001$ \\
\hline HBsAg, $\log 10(\mathrm{IU} / \mathrm{mL})$ & $0.69(0.26-1.83)$ & 0.460 & $0.64(0.24-1.72)$ & 0.382 \\
\hline \multicolumn{5}{|l|}{ Origin $\mathrm{HBeAg}$} \\
\hline Negative & Ref & - & Ref & - \\
\hline Positive & $1.07(0.30-3.80)$ & 0.921 & $1.23(0.17-8.93)$ & 0.838 \\
\hline
\end{tabular}



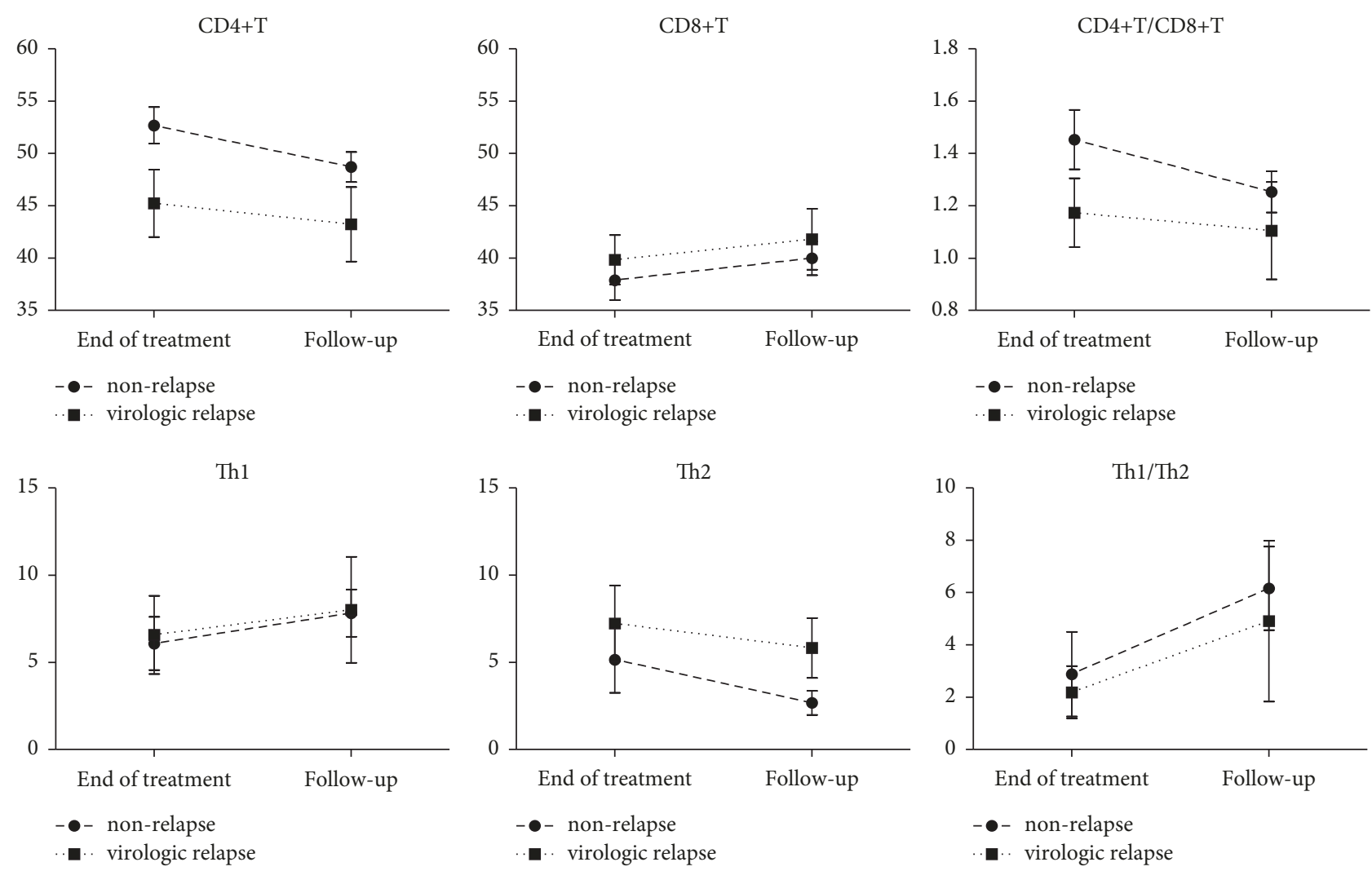

FIgURE 4: Changes in the ratios of $\mathrm{CD}^{+} \mathrm{T}, \mathrm{CD} 8^{+} \mathrm{T}$, Thl, and $\mathrm{Th} 2$ in nonrelapse and virologic relapse patients.

cutoffs chosen by Youden's index of age to virologic relapse, the level of HBsAg to virologic relapse, and the level of HBsAg to clinical relapse were 32.5 years, $2.05 \log 10(\mathrm{IU} / \mathrm{mL})$, and $2.30 \log 10(\mathrm{IU} / \mathrm{mL})$, respectively. All these three ROC results demonstrated good sensitivity (over 0.8 ) but lower specificity (lower than 0.5); however these results still indicated that age and $\mathrm{HBs} A g$ were potential factors in predicting relapse.

\section{Discussion}

In this study, under supervision, none of the patients in our study died or developed cirrhosis, liver failure, or hepatocellular carcinoma. The 48 -week cumulative virologic relapse rates in origin $\mathrm{HBeAg}$ positive and negative $\mathrm{CHB}$ patients were $56.4 \%$ and $73.9 \%$, respectively, which were similar results to a study [13] by Lee et al. and a systematic review [14] by Chang et al., although we strictly followed the 2012 APASL guidelines [5]. Twenty-one (39.1\%) patients required retreatment with NAs. Fortunately, the virologic relapse was controlled by retreatment within 24 weeks.

Increased attention should be paid during the first 24 weeks of the follow-up after NA cessation in origin $\mathrm{HBeAg}$ positive patients, since 16 of $22(72.7 \%)$ virologic relapses and 11 of $14(78.6 \%)$ clinical relapses occurred in these first 24 weeks. Similarly, the first 12 weeks of follow-up after NA cessation also require increased vigilance in origin $\mathrm{HBeAg}$ negative patients, since 14 of 17 (82.4\%) virologic relapses and 6 of $10(60 \%)$ clinical relapses occurred in these first 12 weeks.
The 62 patients could be divided into four categories in this study. We designated Category A as "immune control," since no relapse occurred in the category. We designated Category B as "immune retolerance," since we assumed that the immune status of these patients is similar to "immune tolerance" in childhood during chronic HBV infection with a high load of HBV replication and normal ALT levels. We designated Category C as "immune recontrol," since we assumed that host immunity blocked HBV replication without help from the NA therapy. We designated Category $\mathrm{D}$ as "immune reactivation," since we assumed these patients were similar to naïve patients receiving NA therapy with elevated ALT and HBV DNA levels. The four different immune statuses may relate to the function of $\mathrm{HBV}$-specific $\mathrm{T}$ cells, because the antiviral drug-induced attenuation of viremia provides a window for the reconstitution of the HBVspecific immune response [15]. Further study of $\mathrm{HBV}$-specific $\mathrm{T}$ cell response should be conducted, in order to ascertain the differences between these four categories.

In this study, we found a negative correlation between HBsAg and $\mathrm{CD}^{+} \mathrm{T}$, a positive correlation between $\mathrm{HBsAg}$ and $\mathrm{CD}^{+} \mathrm{T}$, and a negative correlation between HBV DNA and $\mathrm{CD} 4^{+} \mathrm{T}$. In patients with chronic HBV infection, cytotoxic $\mathrm{T}$ cell response is weak [16], especially for virus-specific $\mathrm{T}$ cell response [17]. $\mathrm{CD}^{+} \mathrm{T}$ activity is inhibited by high levels of HBV DNA, microRNA-146a, and immunosuppressive cytokines such as interleukin-10 [18, 19]. Therefore, removal of viral antigens, allowing $\mathrm{T}$ cells to rest, is important for functional reconstitution of $\mathrm{T}$ cell immune response [20]. 


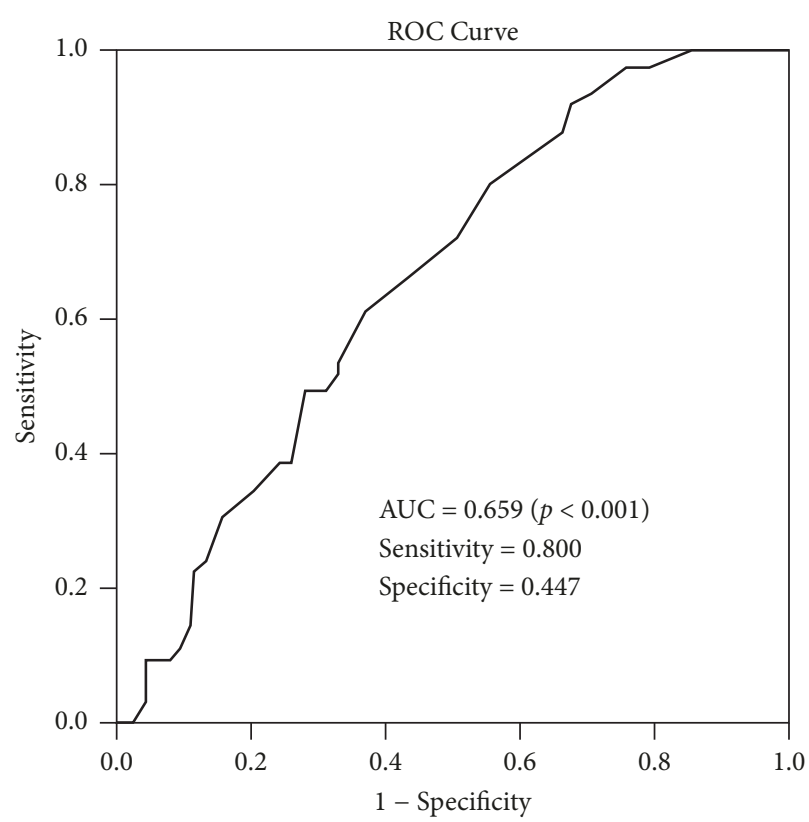

(a)

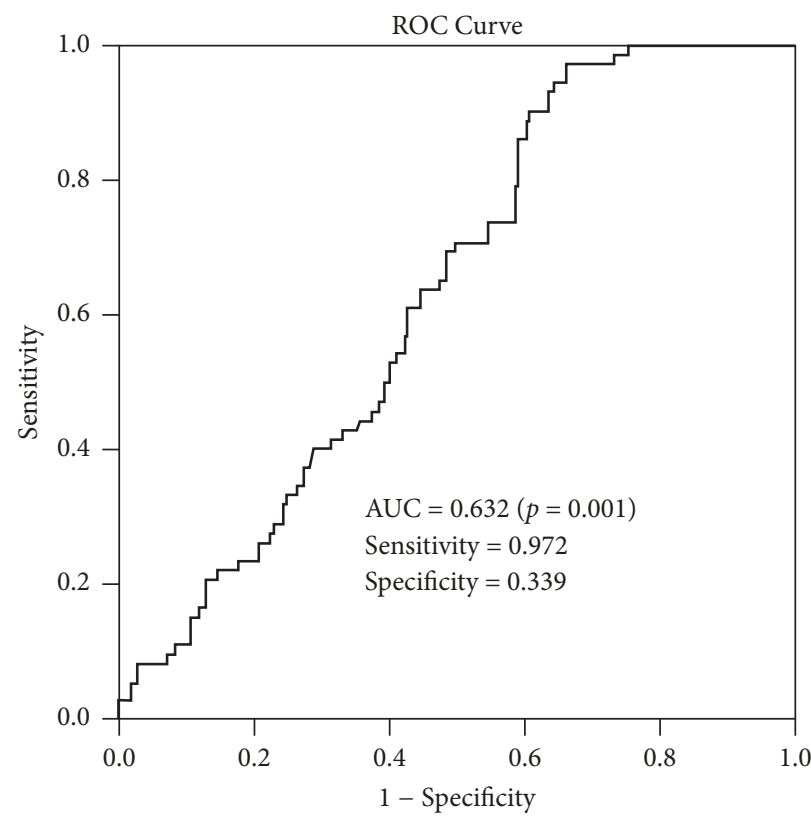

(b)

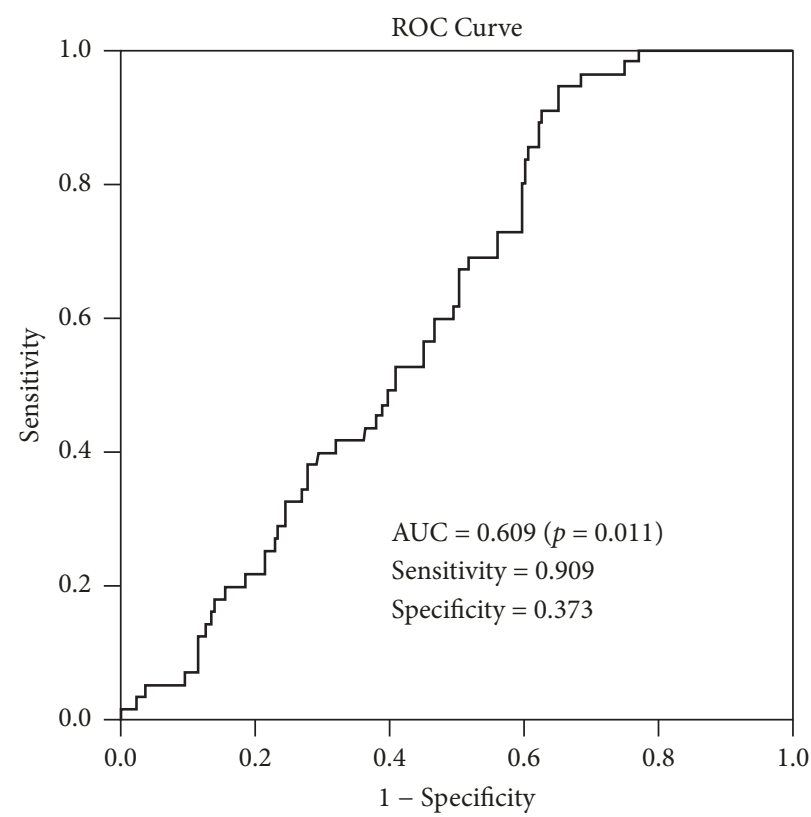

(c)

FIGURE 5: ROC curve and parameters of associated factors, including age to virologic relapse (a), the level of HBsAg to virologic relapse (b), and the level of HBsAg to clinical relapse (c).

The use of NA to reduce viremia helps functional recovery of HBV-specific immune response [15].

HBsAg clearance at the end of treatment indicated successful NA cessation in this study. Higher levels of HBsAg indicated increased risk of virologic relapse. Similar results were reported in some studies [21-23]. In contrast, Seto et al. reported that HBsAg levels at the beginning of entecavir treatment, entecavir cessation, and the subsequent rate of HBsAg reduction were not associated with virologic relapse [24]. The reason for these two opposite opinions is still unclear. HBsAg, which is downstream product of $\mathrm{HBV}$ cccDNA [25-27], may reflect levels of HBV cccDNA [28]. Higher levels of both hepatitis B surface and core-related antigens at the time of NA discontinuation were associated with relapse [28]. Lower end-of-treatment HBsAg levels may contribute to higher cumulative $\mathrm{HBsAg}$ loss rate after NA cessation [29]. A quite lengthy follow-up observation after NA cessation is necessary for evaluating the rate of $\mathrm{HBsAg}$ loss. A randomized controlled study from Berg $\mathrm{T}$ [30] found that HBsAg levels decreased in the 144 weeks follow-up after 
TDF therapy stopped. Study from Hadziyannis et al. [31] showed $39 \%$ of patients lose HBsAg in the 6-year followup after ADV therapy cessation. But it is assumed that NA therapy requires 52.2 years in order to achieve $\mathrm{HBsAg}$ clearance and that a finite treatment duration is unlikely [32]. As HBsAg clearance is not easy to achieve, other predictive factors should be investigated in the clinical practice.

In this study, age was a predictive factor for virologic relapse. Some studies have shown that age $>40$ years predicted relapse in origin $\mathrm{HBeAg}$ positive patients $[9,23$, 33 ]. Age served as a predictor for virologic relapse in origin $\mathrm{HBeAg}$ negative patients in other studies $[21,23]$. We found no other predictive factors for virologic relapse, such as NA treatment duration or duration of negative HBV DNA maintenance. Chaung et al. [10] reported that HBeAg seroconversion and consolidation duration were not predictors for relapse. Findings from Chen et al. suggest that there were no predictive factors for relapse [34]. It seems that prolonged NA treatment or prolonged consolidation treatment cannot reduce the virologic relapse rate, which is not in accordance with the new updates of guidelines, comparing to the old ones, from APASL [35], suggesting more than 3 years of consolidation treatment in origin $\mathrm{HBeAg}$ positive patients to stop NA, or from EASL [36], suggesting more than 3 years of virological suppression in origin $\mathrm{HBeAg}$ negative patients to stop NA. But a systematic review [37] suggests that on-therapy virological remission $(\mathrm{VR})>24$ months offers higher chances of off-NA VR in patients with HBeAg negative chronic hepatitis $\mathrm{B}$.

As mentioned above, there are difficulties to stop NA therapy without relapse. Discontinuation of NA therapy in $\mathrm{CHB}$ continues to be a hot topic with contrasting views in the recent liver meeting: patients may benefit from NA therapy cessation [38]; however there is no robust evidence to support treatment discontinuation [39].

This study has some limitations. First, the case number was small, since we recruited patients from only one center. Second, pretreatment HBV genotype results were not carried out, since diagnostic reagents were scarce and HBV genotype was not a routine test in the past ten years in China which is still a developing country. Third, further study on HBVspecific cytotoxic T lymphocytes immune response was not carried out.

\section{Conclusion}

NA cessation is safe under supervision. Increased vigilance was required in the first 24 weeks in origin $\mathrm{HBeAg}$ positive patients and the first 12 weeks in negative patients. Age, HBsAg level before NA cessation, and origin HBeAg status before NA treatment can be predictive factors for virologic relapse. HBV DNA can be predictive factor for retreatment.

\footnotetext{
Abbreviations

NA: Nucleos(t)ide analogues

HBV: Hepatitis B virus

CHB: Chronic hepatitis B

HCC: Hepatocellular carcinoma
}
ETV: $\quad$ Entecavir
LDT: Telbivudine
LAM: Lamivudine
ADV: Adefovir dipivoxil
TDF: Tenofovir disoproxil fumarate
HBsAg: Hepatitis B surface antigen
HBeAg: Hepatitis B e antigen
AST: Aspartate transaminase
ALT: Alanine transaminase
CD4 ${ }^{+} \mathrm{T}$ : CD4 positive $\mathrm{T}$ lymphocytes
$\mathrm{CD}^{+} \mathrm{T}$ : CD8 positive $\mathrm{T}$ lymphocytes
Th1: $\quad$ Type 1 helper T lymphocytes
Th2: $\quad$ Type 2 helper T lymphocytes
ULN: Upper limit of normal
EOT: End of treatment
VR: Virological remission.

\section{Conflicts of Interest}

The authors declare that there are no conflicts of interest regarding the publication of this article.

\section{Acknowledgments}

Thanks are due to Pan Shun-wen and Li Wan-tao of the laboratory of Third Affiliated Hospital of Sun Yatsen University. This study was supported by Plan of Science and Technology of Guangdong (nos. 411308023039 and 2016A020215221), Guangzhou Science and Technology Project (nos. 201508020118 and 2014Y2-00544), the National Natural Science Foundation of China (nos. 81570539 and 81370535), and the Fundamental Research Funds for the Central Universities (Precision Medicine and Biological Big Data) (no. 15ykjc21d).

\section{References}

[1] J. J. Ott, G. A. Stevens, J. Groeger, and S. T. Wiersma, “Global epidemiology of hepatitis B virus infection: new estimates of age-specific HBsAg seroprevalence and endemicity," Vaccine, vol. 30, no. 12, pp. 2212-2219, 2012.

[2] J. L. Dienstag, "Benefits and risks of nucleoside analog therapy for hepatitis B," Hepatology, vol. 49, no. 5, pp. S112-S121, 2009.

[3] B. Werle-Lapostolle, S. Bowden, S. Locarnini et al., "Persistence of cccDNA during the natural history of chronic hepatitis B and decline during adefovir dipivoxil therapy," Gastroenterology, vol. 126, no. 7, pp. 1750-1758, 2004.

[4] Chinese Society of Hepatology, Chinese Society of Infectious Diseases, and Chinese Medical Association, "The guideline of prevention and treatment for chronic hepatitis B (2010 version)," Chinese Journal of Hepatology, vol. 19, no. 1, pp. 1324, 2011.

[5] Asian Pacific Association for the Study of the Liver, "AsianPacific consensus statement on the management of chronic hepatitis B: a 2012 update," Hepatology International, vol. 6, pp. 531-561, 2012.

[6] European Association for the Study of the Liver, "EASL clinical practice guidelines: management of chronic hepatitis B virus infection," Journal of Hepatology, vol. 57, no. 1, pp. 167-185, 2012. 
[7] A. S. F. Lok and B. J. McMahon, "Chronic hepatitis B: update 2009," Hepatology, vol. 50, no. 3, pp. 661-662, 2009.

[8] World Health Organization, "Guidelines for the prevention, care and treatment of persons with chronic hepatitis B infection," 2015, http://www.who.int/hepatitis/ publications/hepatitis-b-guidelines/en/.

[9] M. J. Song, D. S. Song, H. Y. Kim et al., "Durability of viral response after off-treatment in $\mathrm{HBeAg}$ positive chronic hepatitis B," World Journal of Gastroenterology, vol. 18, no. 43, pp. 6277-6283, 2012.

[10] K. T. Chaung, N. B. Ha, H. N. Trinh et al., "High frequency of recurrent viremia after hepatitis $\mathrm{B}$ e antigen seroconversion and consolidation therapy," Journal of Clinical Gastroenterology, vol. 46, no. 10, pp. 865-870, 2012.

[11] Y. J. Kim, K. Kim, S. H. Hwang et al., "Durability after discontinuation of nucleos(t)ide therapy in chronic HBeAg negative hepatitis patients.," Clinical and Molecular Hepatology, vol. 19, no. 3, pp. 300-304, 2013.

[12] W.-J. Jeng, I.-S. Sheen, Y.-C. Chen et al., "Off-therapy durability of response to entecavir therapy in hepatitis $\mathrm{B}$ e antigennegative chronic hepatitis B patients," Hepatology, vol. 58, no. 6, pp. 1888-1896, 2013.

[13] I.-C. Lee, C.-K. Sun, C.-W. Su et al., "Durability of Nucleos(t)ide analogues treatment in patients with chronic hepatitis B," Medicine (United States), vol. 94, no. 32, Article ID e1341, 2015.

[14] M.-L. Chang, Y.-F. Liaw, and S. J. Hadziyannis, "Systematic review: Cessation of long-term nucleos(t)ide analogue therapy in patients with hepatitis $\mathrm{B}$ e antigen-negative chronic hepatitis B," Alimentary Pharmacology \& Therapeutics, vol. 42, no. 3, pp. 243-257, 2015.

[15] E. Zhang, A. Kosinska, M. Lu, H. Yan, and M. Roggendorf, "Current status of immunomodulatory therapy in chronic hepatitis B, fifty years after discovery of the virus: Search for the "magic bullet" to kill cccDNA," Antiviral Research, vol. 123, pp. 193-203, 2015.

[16] B. Rehermann, P. Fowler, J. Sidney et al., "The cytotoxic T lymphocyte response to multiple hepatitis B virus polymerase epitopes during and after acute viral hepatitis," The Journal of Experimental Medicine, vol. 181, no. 3, pp. 1047-1058, 1995.

[17] M. C. Jung, U. Spengler, W. Schraut et al., "Hepatitis B virus antigen-specific T-cell activation in patients with acute and chronic hepatitis B," Journal of Hepatology, vol. 13, no. 3, pp. 310317, 1991.

[18] Y. Sobao, H. Tomiyama, K. Sugi et al., "The role of hepatitis $\mathrm{B}$ virus-specific memory CD8 T cells in the control of viral replication," Journal of Hepatology, vol. 36, no. 1, pp. 105-115, 2002.

[19] S. Wang, X. Zhang, Y. Ju et al., "MicroRNA-146a feedback suppresses $\mathrm{T}$ cell immune function by targeting Statl in patients with chronic hepatitis B," The Journal of Immunology, vol. 191, no. 1, pp. 293-301, 2013.

[20] A. Bertoletti and C. Ferrari, "Innate and adaptive immune responses in chronic hepatitis B virus infections: towards restoration of immune control of viral infection," Gut, vol. 61, no. 12, pp. 1754-1764, 2012.

[21] F. Liu, L. Wang, X. Y. Li et al., "Poor durability of lamivudine effectiveness despite stringent cessation criteria: a prospective clinical study in hepatitis B e antigen-negative chronic hepatitis B patients," Journal of Gastroenterology and Hepatology, vol. 26, no. 3, pp. 456-460, 2011.

[22] Y. Liang, J. Jiang, M. Su et al., "Predictors of relapse in chronic hepatitis B after discontinuation of anti-viral therapy,"
Alimentary Pharmacology and Therapeutics, vol. 34, pp. 344352, 2011.

[23] C.-H. Chen, C.-H. Hung, T.-H. Hu et al., "Association between level of hepatitis B surface antigen and relapse after entecavir therapy for chronic hepatitis B virus infection," Clinical Gastroenterology and Hepatology, vol. 13, no. 11, pp. 1984-1992.e1, 2015.

[24] W.-K. Seto, A. J. Hui, V. W.-S. Wong et al., “Treatment cessation of entecavir in Asian patients with hepatitis B e antigen negative chronic hepatitis B: a multicentre prospective study," Gut, vol. 64, no. 4, pp. 667-672, 2015.

[25] E. Tanaka and A. Matsumoto, "Guidelines for avoiding risks resulting from discontinuation of nucleoside/nucleotide analogs in patients with chronic hepatitis B," Hepatology Research, vol. 44, no. 1, pp. 1-8, 2014.

[26] H.-C. Yang and J.-H. Kao, "Persistence of hepatitis B virus covalently closed circular DNA in hepatocytes: Molecular mechanisms and clinical significance," Emerging Microbes and Infections, vol. 3, no. 9, article e64, 2014.

[27] C.-M. Tang, T. O. Yau, and J. Yu, "Management of chronic hepatitis B infection: current treatment guidelines, challenges, and new developments," World Journal of Gastroenterology, vol. 20, no. 20, pp. 6262-6278, 2014.

[28] A. Matsumoto, E. Tanaka, Y. Suzuki et al., "Combination of hepatitis B viral antigens and DNA for prediction of relapse after discontinuation of nucleos(t)ide analogs in patients with chronic hepatitis B," Hepatology Research, vol. 42, no. 2, pp. 139149, 2012.

[29] C. H. Chen, C. H. Hung, J. H. Wang, S. Lu, T. Hu, and C. Lee, "Long-term incidence and predictors of hepatitis B surface antigen loss after discontinuing nucleoside analogues in noncirrhotic chronic hepatitis B patients," Clinical Microbiology and Infection, 2017.

[30] T. Berg, K.-G. Simon, S. Mauss et al., "Long-term response after stopping tenofovir disoproxil fumarate in non-cirrhotic HBeAg-negative patients-FINITE study," Journal of Hepatology, vol. 67, no. 5, pp. 918-924, 2017.

[31] S. J. Hadziyannis, V. Sevastianos, I. Rapti, D. Vassilopoulos, and E. Hadziyannis, "Sustained responses and loss of HBsAg in $\mathrm{HBeAg}$-negative patients with chronic hepatitis B who stop long-term treatment with adefovir," Gastroenterology, vol. 143, no. 3, pp. 629-636, 2012.

[32] S. Chevaliez, C. Hézode, S. Bahrami, M. Grare, and J.-M. Pawlotsky, "Long-term hepatitis B surface antigen (HBsAg) kinetics during nucleoside/nucleotide analogue therapy: Finite treatment duration unlikely," Journal of Hepatology, vol. 58, no. 4, pp. 676-683, 2013.

[33] H. W. Lee, H. J. Lee, J. S. Hwang et al., "Lamivudine maintenance beyond one year after $\mathrm{HBeAg}$ seroconversion is a major factor for sustained virologic response in $\mathrm{HBeAg}$-positive chronic hepatitis B," Hepatology, vol. 51, no. 2, pp. 415-421, 2010.

[34] D.-B. Chen, Y.-M. Chen, J. Liu et al., "Durability of efficacy after telbivudine off-treatment in chronic hepatitis B patients," Journal of Clinical Virology, vol. 59, no. 1, pp. 50-54, 2014.

[35] Asian Pacific Association for the Study of the Liver, "AsianPacific clinical practice guidelines on the management of hepatitis B: a 2015 update," Hepatology International, vol. 10, pp. 1-98, 2016.

[36] European Association for the Study of the Liver, "EASL 2017 Clinical Practice Guidelines on the management of hepatitis B virus infection," Journal of Hepatology, vol. 67, no. 2, pp. 370398, 2017. 
[37] G. Papatheodoridis, I. Vlachogiannakos, E. Cholongitas et al., "Discontinuation of oral antivirals in chronic hepatitis B: a systematic review," Hepatology, vol. 63, no. 5, pp. 1481-1492, 2016.

[38] F. van Bömmel and T. Berg, "Stopping long-term treatment with nucleos(t)ide analogues is a favourable option for selected patients with $\mathrm{HBeAg}$-negative chronic hepatitis B," Liver International, vol. 38, supplement 1, pp. 90-96, 2018.

[39] S. Marciano and A. Gadano, "Why not to stop antiviral treatment in patients with chronic hepatitis B," Liver International, vol. 38, pp. 97-101, 2018. 


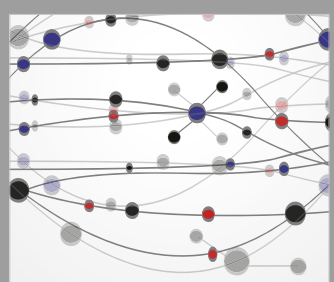

The Scientific World Journal
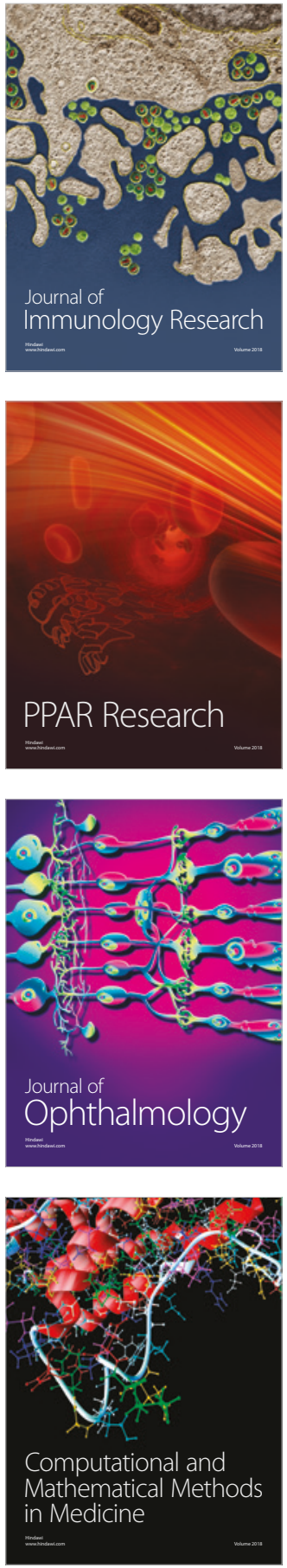

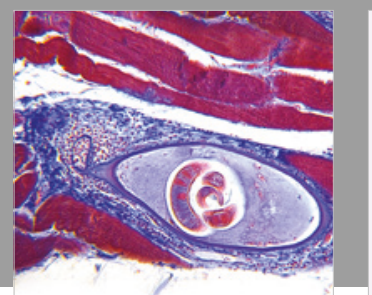

Gastroenterology Research and Practice

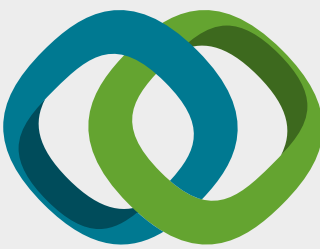

\section{Hindawi}

Submit your manuscripts at

www.hindawi.com
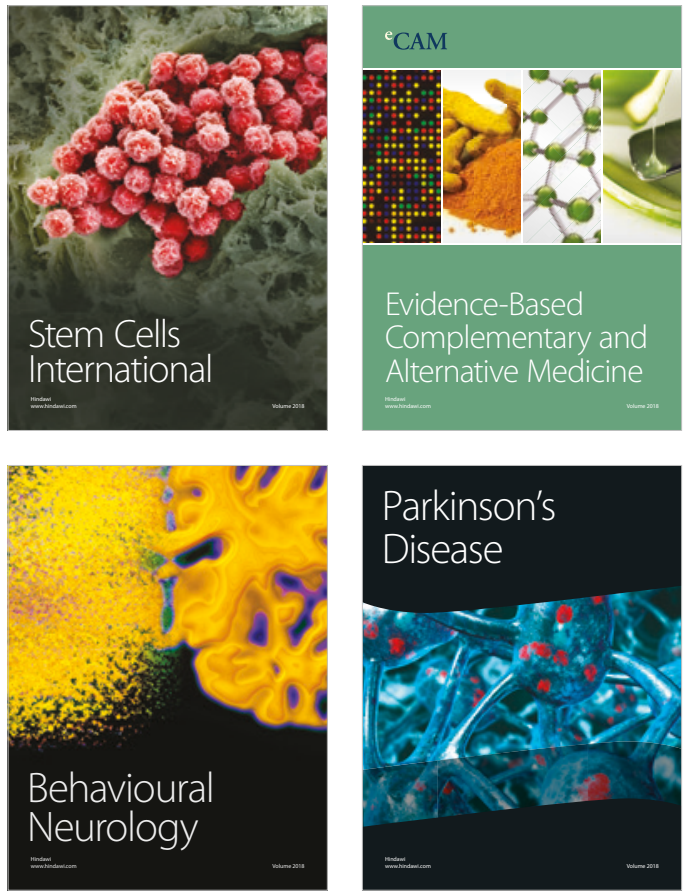

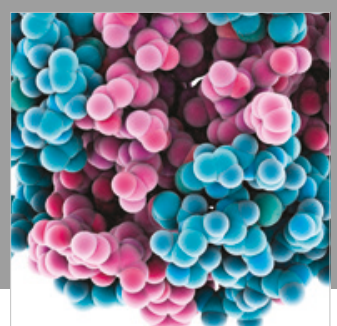

ournal of

Diabetes Research

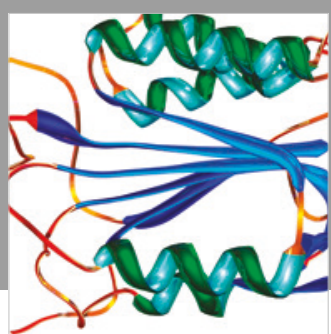

Disease Markers
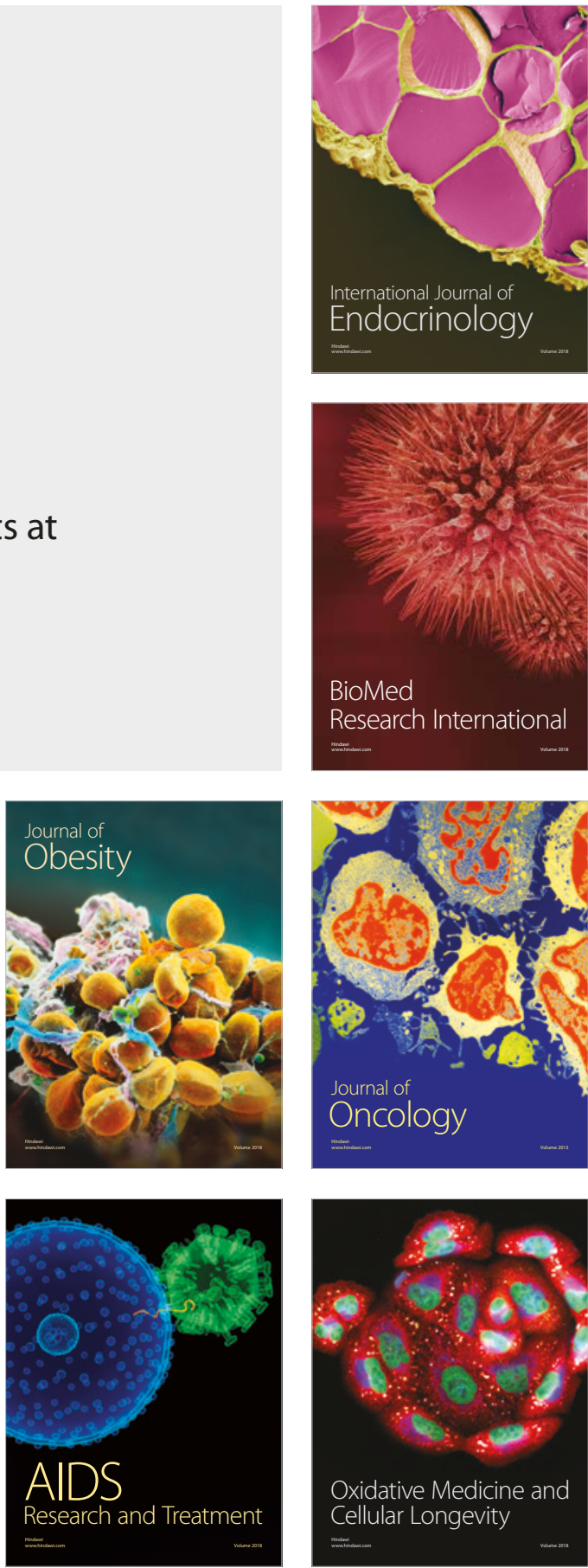